\title{
COMPARISON OF STATIC FORCE EXERTED BY FLUIDIC MUSCLE AND SHADOW AIR MUSCLE ${ }^{1}$ J. Sárosi, ${ }^{2}$ L. György \\ ${ }^{1}$ Technical Institute, Faculty of Engineering, University of Szeged, Moszkvai krt. 9,6725, Szeged, Hungary, e-mail: sarosi@mk.u-szeged.hu \\ ${ }^{2}$ ContiTech Fluid Automotive Hungária Ltd., Rákosi út 3, 6900, Makó, Hungary, e-mail:1.gyorgy90@gmail.com
}

\begin{abstract}
Many researchers have investigated different properties and behaviour of pneumatic muscles actuators (PMAs). Most of them have dealt with the force-contraction (force-relative displacement) characteristics or control of PMAs. In this paper two different type PMAs are compared: Fluidic Muscle made by Festo Company and Shadow Air Muscle made by Shadow Robot Company. The most relevant difference between them can be noticed in their structure. The Fluidic Muscle is an embedded muscle which means the load carrying element is embedded in its membrane, while Shadow Air Muscle is a netted muscle, but in its non-loaded condition there is a gap between the membrane and the load carrying element. Among other things, force developed by pneumatic muscle actuators depends on applied pressure, contraction, geometry and the used materials. As it is described in this paper, they show significantly different forcecontraction characteristics despite having similar dimensional properties. These characteristics are determined by experimental measurement.
\end{abstract}

Keywords: pneumatic muscle actuators, Fluidic Muscle, Shadow Air Muscle, force-contraction characteristics

\section{INTRODUCTION}

Nowadays, various types of actuators are used in industry such as electric, hydraulic and pneumatic. Because of their disadvantages magnetostrictive, piezoelectric, polymeric and shape memory alloy actuators are also notable in some applications [1]. Pneumatic muscle actuators are less known pneumatic actuator. They are tube-like actuators which contract axially and expand radially when inflated. They are operated by gas (usually air). Throughout literature, various names have been used to identify a PMA, which are Pneumatic Artificial Muscle, Fluid Actuator, Fluid-Driven Tension Actuator, Axially Contractible Actuator and Tension Actuator. For these actuators several names have been given by the manufacturer or inventor like Air Muscle, Fluidic Muscle, Rubbertuator, Pleated Pneumatic Artificial Muscle, etc. [2], [3]. The structure of the most PMAs can be divided into two main parts: a flexible membrane (e.g. latex, silicone rubber, chloroprene) and a load carrying element (e.g. nylon, fiberglass, aramid). On the basis of their connection, Daerden in [4] discriminates braided muscles, netted muscles and embedded muscles (Fig. 1).

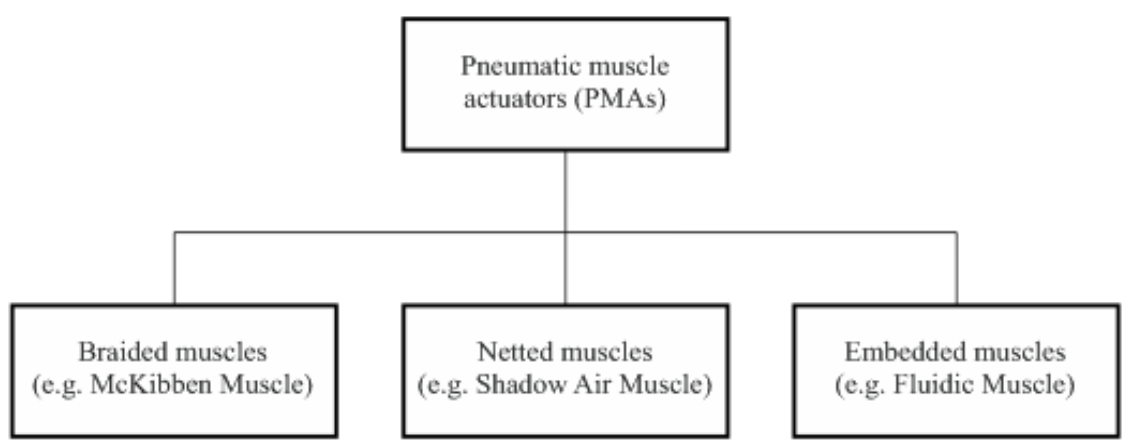

Figure 1. Three classes of PMAs based on [4] 
PMAs have no inner moving parts and there is no sliding on the surfaces. Besides, they have small weight, simple construction and low cost. During action they reach high velocities, while the power/weight and the power/volume ratios reach high levels. The main drawbacks are nonlinear and time variable behaviour, existence of hysteresis and step-jump pressure. It is also necessary to emphasize that PMA is a one-way acting actuator and it produces linear motion only. For two-direction motion an antagonistic pair of PMAs or a spring returned PMA has to be used [5], [6].

This paper is organized in 4 sections. After Introduction, in the Section 2, the applied experimental rig and the experimental measurements are described. The experimental results and the comparisons of Fluidic Muscle and Shadow Air Muscle are shown in Section 3. The paper ends with Conclusions (Section 4).

\section{MATERIALS AND METHODS}

The scheme of a test bed for pressure, force and position measuring is plotted in Fig. 2. The proportional pressure regulator is Festo VPPM-6L-L-1-G1/8-0L6H-V1N-S1C1, the incremental encoder is LINIMIK MSA 320, the load cell is Kaliber 7923 and the pressure sensor is Motorola MPX5999D [7].

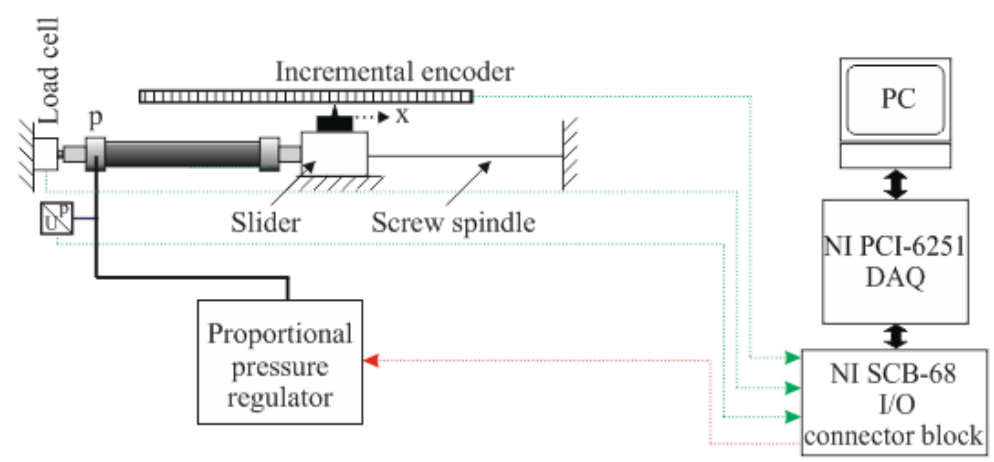

Figure 2. Scheme of the test bed

The Fluidic Muscle and Shadow Air Muscle (Fig. 3 and Tab. 1) are settled on the test bed, respectively. One of ends of PMAs is fixed while the other is movable. The free end of PAMs is connected with a spindle which is connected with an accurate position measuring instrument. Based on values in 30 points of PMA measured for various compressions the force-contraction curve is plotted. Measurements at every point is repeated 5 times and statistically averaged. The measurement and data acquisition is performed using LabVIEW.
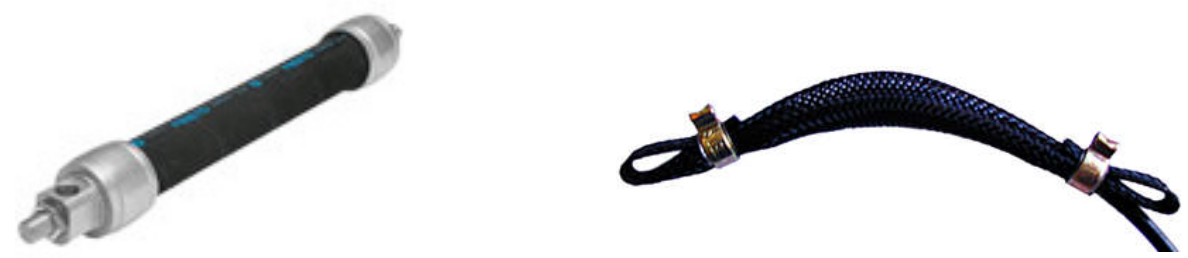

Figure 3. Fluidic Muscle (left) and Shadow Air Muscle (right) [8], [9] 
Table 1. General data of the applied PMAs

\begin{tabular}{|l|c|c|}
\hline & Fluidic Muscle & Shadow Air Muscle \\
\hline Inner diameter $[\mathrm{mm}]$ & 20 & 20 \\
\hline Nominal length $[\mathrm{mm}]$ & 200 & 210 \\
\hline Max. pressure $[\mathrm{kPa}]$ & 600 & 350 \\
\hline Max. additional load $[\mathrm{kg}]$ & 80 & 20 \\
\hline
\end{tabular}

Chloroprene is used as an elastomer and aramid is used as a reinforcing fibre (load carrying element) for the Fluidic Muscle [10]. The Shadow Air Muscle includes rubber and nylon [11]. Another basic difference between the Fluidic Muscle and Shadow Air Muscle is that Shadow Air Muscle requires a certain load at initial position [12].

\section{EXPERIMENTAL RESULTS}

The most important property of a PMA is the static force-contraction function which depends on the pressure. Fig. 4a shows that the maximal force developed by Fluidic Muscle is reached by increasing the length, while the minimal value $\mathrm{F}=0 \mathrm{~N}$ is for maximal contraction when the length is minimal. For the pressure of $500 \mathrm{kPa}$ the measured maximal force is $2048,33 \mathrm{~N}$, and the maximal contraction is $25,88 \%$. The smallest maximal force is $503,24 \mathrm{~N}$ which corresponds with the pressure $\mathrm{p}=0 \mathrm{kPa}$. Characteristic curves are given for the interval of $0-500 \mathrm{kPa}$ for $0 \mathrm{kPa}, 50 \mathrm{kPa}, 100 \mathrm{kPa}, 150 \mathrm{kPa}, 200 \mathrm{kPa}, 250 \mathrm{kPa}$, $300 \mathrm{kPa}, 350 \mathrm{kPa}, 400 \mathrm{kPa}, 450 \mathrm{kPa}$ and $500 \mathrm{kPa}$. The hysteresis (Fig. 4b) occurs due to friction between the tube and the overall net, friction in threads in contact and according to deformation of the body made of viscoelastic material. For simplicity the next curves are depicted only for $0 \mathrm{kPa}, 100 \mathrm{kPa}, 200 \mathrm{kPa}$, $300 \mathrm{kPa}, 400 \mathrm{kPa}$ and $500 \mathrm{kPa}$.
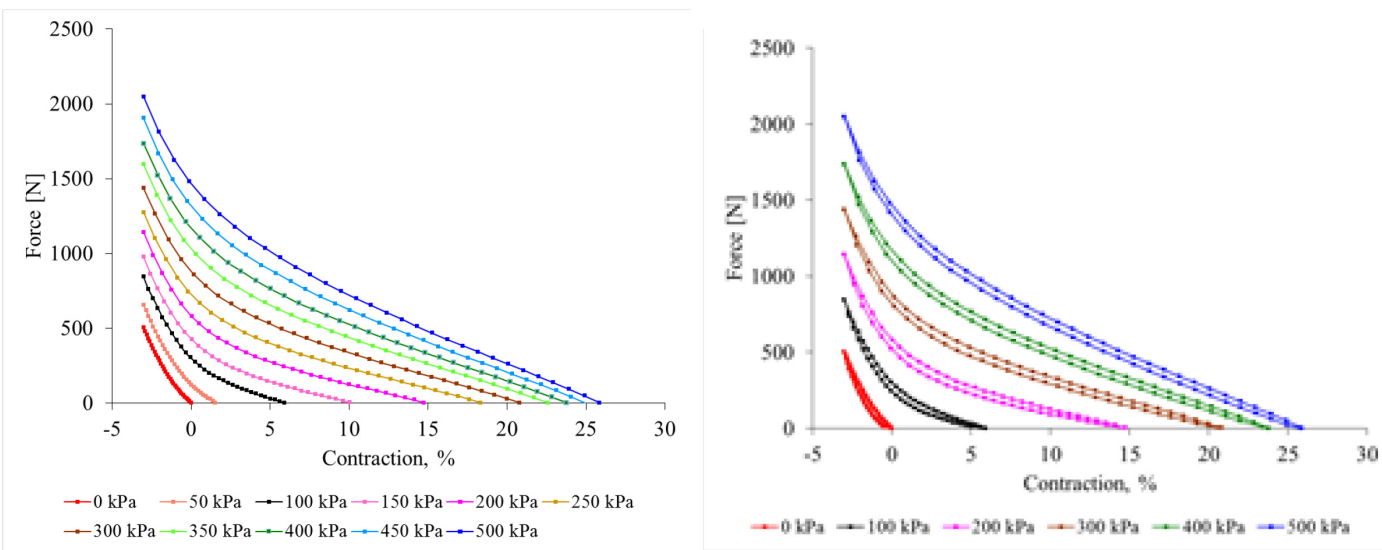

Figure 4.

a, Static force-contraction curves for the pressure in the interval of 0-500 $\mathrm{kPa}$ with increase of $50 \mathrm{kPa}$ (Fluidic Muscle) b, Hysteresis for constant pressures (Fluidic Muscle)

For the measurement of Shadow Air Muscle the maximal force load of the muscle is limited to $250 \mathrm{~N}$. In Fig. $5 \mathrm{a}$ it is shown that the maximal contraction is $37 \%$ for the pressure of $350 \mathrm{kPa}$. Characteristic curves are given for the interval of $0-350 \mathrm{kPa}$ for $0 \mathrm{kPa}, 50 \mathrm{kPa}, 100 \mathrm{kPa}, 150 \mathrm{kPa}, 200 \mathrm{kPa}, 250 \mathrm{kPa}, 300 \mathrm{kPa}$ and $350 \mathrm{kPa}$. The hysteresis curves (Fig. 5b) are depicted only for $0 \mathrm{kPa}, 100 \mathrm{kPa}, 200 \mathrm{kPa}$ and $300 \mathrm{kPa}$. 

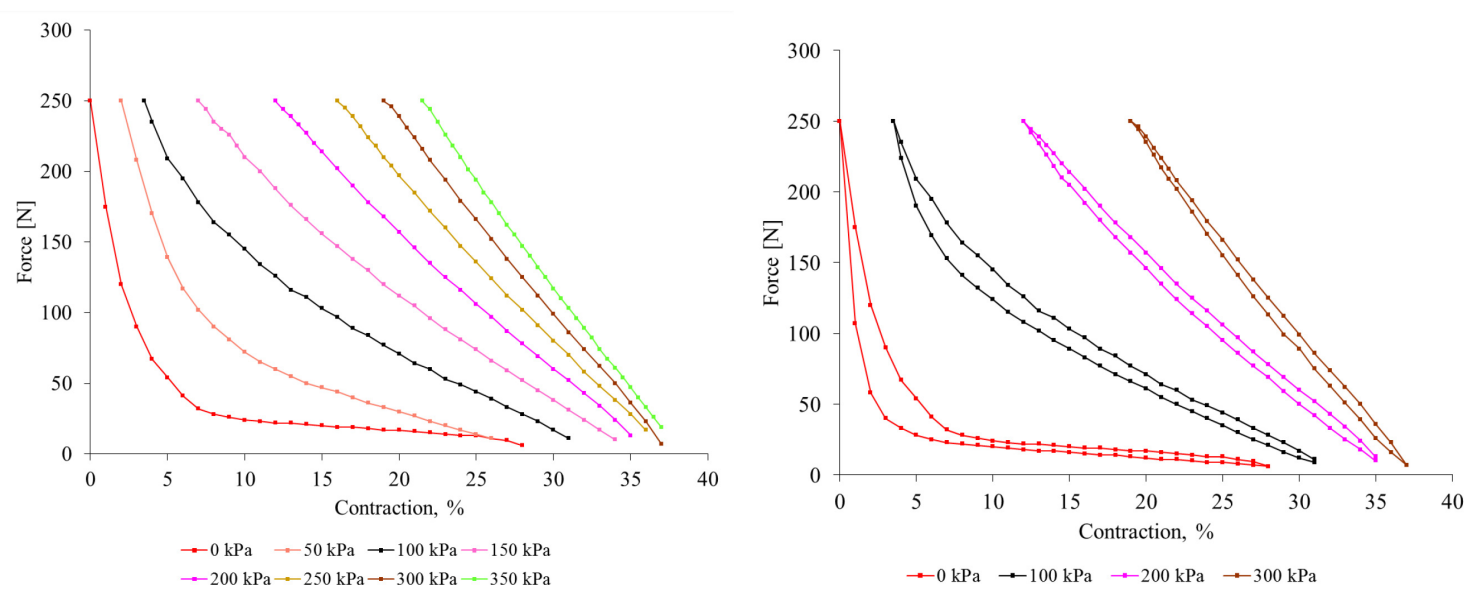

Figure 5.

a, Static force-contraction curves for the pressure in the interval of 0-350 $\mathrm{kPa}$ with increase of $50 \mathrm{kPa}$ (Shadow Air Muscle) b, Hysteresis for constant pressures (Shadow Air Muscle)

\section{CONCLUSIONS}

Based on these experiments, the following is concluded: the investigated muscles have similar dimensional properties but they can be used for different areas. The Shadow Air Muscle with $20 \mathrm{~mm}$ inner diameter cannot be considered as a robust construction and cannot be used for industrial tasks. Because of its relatively low price its usage can be suitable for hobby projects. The Fluidic Muscle with $20 \mathrm{~mm}$ inner diameter is a well-constructed robust muscle, definitely developed for industrial usage, capable of exerting large amount of force which has been confirmed in this study.

\section{REFERENCES}

[1] D. G. Caldwell, G. A. Medrano-Cerda, M. Goodwin, Control of Pneumatic Muscle Actuators, IEEE Control Systems Magazine, 15 (1), (1995), pp. 40-48.

[2] R. Ramasary, M. R. Juhari, M. R. Mamat, S. Yaacob, N. F. Mohd Nasir, M. Sugisaka, An Application of Finite Modelling to Pneumatic Artificial Muscle, American Journal of Applied Sciences, 2 (11), (2005), pp. 1504-1508.

[3] D. H. Plettenburg, Pneumatic Actuators: a Comparison of Energy-to-Mass Ratio's, IEEE 9th International Conference on Rehabilitation Robotics, Chicago, IL, USA, 28 Jun - 1 July, 2005, pp. 545-549.

[4] D. Daerden, Conception and Realization of Pleated Artificial Muscles and Their Use as Compliant Actuation Elements, PhD Dissertation, Vrije Universiteit Brussel, Faculteit Toegepaste Wetenschappen Vakgroep Werktuigkunde, 1999

[5] M. Tothova, J. Pitel, Operating Characteristics of Antagonistic Actuator with Pneumatic Artificial Muscles, Applied Mechanics and Materials, 616 (2014), pp. 101-109.

[6] J. Sárosi, S. Csikós, I. Asztalos, J. Gyeviki, A. Véha, Accurate Positioning of Spring Returned Pneumatic Artificial Muscle Using Sliding-mode Control, 1st Regional Conference - Mechatronics in Practice and Education (MECH-CONF 2011), Subotica, Serbia, 8-10 December, 2011, pp. 350-356.

[7] P. Toman, J. Gyeviki, T. Endrődy, J. Sárosi, A. Véha, Design and Fabrication of a Test-bed Aimed for Experiment with Pneumatic Artificial Muscle, International Journal of Engineering, Annals of Faculty of Engineering Hunedoara, 7 (4), (2009), pp. 91-94.

[8] http://www.shadow.org.uk/

[9] http://www.festo.com 
[10]S. Hesse, The Fluidic Muscle in Application, 150 Practical Examples Using the Pneumatic Muscle, Blue Digest on Automation, Festo, Esslingen, 2003

[11] Shadow Dexterous Hand Technical Specification http://www.shadowrobot.com/wpcontent/uploads/shadow_dexterous_hand_technical_specification_E1_20130101.pdf

[12] J. Borzikova, M. Balara, J. Pitel, The Mathematical Model of Contraction Characteristic k = (F, p) of the Pneumatic Artificial Muscle, XXXII. Seminar ASR '2007 „Instruments and Control”, Farana, Smutný, Kočí \& Babiuch, Ostrava, Czech Republic, 27 April, 2007, pp. 21-25. 